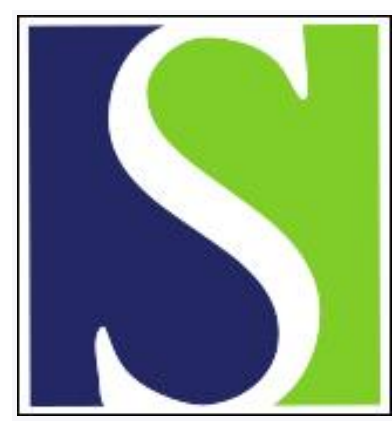

Scand J Work Environ Health 2005;31(3):191-204

https://doi.org/10.5271/sjweh.869

Issue date: Jun 2005

Implementation of participatory ergonomics intervention in construction companies

by van der Molen HF, Sluiter JK, Hulshof CTJ, Vink P, van Duivenbooden C, Holman R, Frings-Dresen MHW

The following articles refer to this text: 2009;35(5):321-324;

2015;41(2):111-123; 2015;41(3):223-233

Key terms: construction company; construction work; ergonomic measure; intervention; participatory ergonomics; randomized controlled trial

This article in PubMed: www.ncbi.nlm.nih.gov/pubmed/15999571

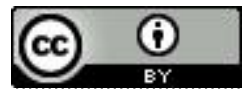




\title{
Implementation of participatory ergonomics intervention in construction companies
}

\author{
by Henk F van der Molen, PhD, 1,2 Judith K Sluiter, PhD, ${ }^{1}$ Carel TJ Hulshof, PhD, ${ }^{1}$ Peter Vink, PhD, ${ }^{3}$ Cor \\ van Duivenbooden, MD, ${ }^{2}$ Rebecca Holman, MMath, ${ }^{4}$ Monique HW Frings-Dresen, PhD ${ }^{1}$
}

\begin{abstract}
van der Molen HF, Sluiter JK, Hulshof CTJ, Vink P, van Duivenbooden C, Holman R, Frings-Dresen MHW. Implementation of participatory ergonomics intervention in construction companies. Scand J Work Environ Health 2005;31(3):191-204.
\end{abstract}

\begin{abstract}
Objectives The effectiveness of the implementation of participatory ergonomics intervention to reduce physical work demands in construction work was studied.

Methods In a cluster randomized controlled trial, 10 bricklaying companies were randomly assigned either to an intervention group $(\mathrm{N}=5)$ or a control group $(\mathrm{N}=5)$. The intervention strategy used a consultant-guided sixstep approach in which company stakeholders participated. Bricklayers and bricklayers' assistants in the intervention group $(\mathrm{N}=65)$ and the control group $(\mathrm{N}=53)$ were followed for 6 months, and their use of four ergonomic measures (adjusting work height when picking up bricks and mortar, adjusting work height for bricklaying at a wall side, mechanizing brick transport, and mechanizing mortar transport) was compared. The use of the ergonomic measures was assessed from worksite observations and questionnaires at baseline and after 6 months. The workers' and employers' behavioral change phases were determined by questionnaires and interviews, respectively. Performance indicators were assessed for the intervention from the researchers' observations during the implementation process and through questionnaires completed by the workers.

Results The strategy had no statistically significant effect on the use of any of the four ergonomic measures, at either the cluster or the individual level. None of the companies in the intervention group passed through all six steps of the intervention. Process outcomes suggest that the ability to use ergonomic measures increased. In bricklaying, self-efficacy and skills to adapt the work height on the scaffolding improved significantly.

Conclusions The intervention did not lead to greater use of ergonomic measures in bricklaying or the transport of materials. Performance indicators of intervention and the corresponding behavioral change phases of stakeholders can help to detect essential elements of such intervention.
\end{abstract}

Key terms construction work; ergonomic measures; randomized controlled trial.

The 12-month prevalence of sustained or regular lower back complaints among Dutch bricklayers and bricklayers' assistants is $45 \%$, while shoulder complaints, at $27 \%$, have been reported as the second most common musculoskeletal disorder (1). The 12-month prevalence of any back and shoulder complaints in Dutch bricklaying teams is consistent with the bricklayer figures reported in countries such as Sweden $(2,3)$ and the United States [bricklayers (4) and bricklayers' assistants (5)]. Physical work demands, especially at higher exposure levels, are considered the main risk factor for work-related musculoskeletal disorders $(6,7)$. In order to reduce the physical work demands of handling materials manually and, indirectly, musculoskeletal disorders among bricklayers and bricklayers' assistants, the Dutch government, the employers' association, and employee organizations agreed on a covenant (2000-2005) to increase the use of ergonomic measures (8). Knowledge about effective preventive measures to reduce the physical work demands and musculoskeletal disorders of bricklayers and their assistants and about effective intervention strategies to implement these measures at worksites

1 Academic Medical Center, Universiteit von Amsterdam, Department: Coronel Institute for Occupational and Environmental Health, AmCOGG, Research Institute Amsterdam, Amsterdam, The Netherlands.

2 Arbouw, Amsterdam, The Netherlands.

3 Technical University Delft / Industrial Design, Delft, The Netherlands.

4 Department of Clinical Epidemiology and Biostatistics, Academic Medical Centre / AmCOGG / University of Amsterdam, Amsterdam, The Netherlands.

Reprint requests to: Dr HF van der Molen, Coronel Institute for Occupational and Environmental Health, Academic Medical Centre, PO Box 22700 NL-1100 DE Amsterdam, The Netherlands. [E-mail: h.f.vandermolen@amc.uva.nl] 
is necessary so that intervention can be planned and carried out on a larger scale.

In general, a combination of technical aids (eg, lifting equipment), facilitated by the implementation of participatory ergonomics intervention with direct worker involvement, seems to be the best form of intervention to reduce physical work demands (9). Equipment for adjusting work height and mechanizing the transport of materials is available for bricklayers and bricklayers' assistants and has proved effective in reducing the frequency and duration of back flexion and the manual handling of objects (10). However, knowledge about effective strategies for implementing ergonomic measures at worksites is scarce. Many institutions (11) and researchers suggest a participatory approach to develop and implement preventive measures in general $(12,13)$ and to reduce the physical work demands of manually handling objects at work (14-19).

Although the implementation of a participatory ergonomics strategy has often been advocated and such a strategy has been used in daily work, its effectiveness has seldom been studied. In addition, the essential elements of such an approach remain unclear $(20,21)$. Evaluation studies on such strategies have had major methodological flaws, such as the absence of a control group or insufficient description of the intervention and the intervention process $(13,22)$. Evaluating the implementation of participatory (ergonomics) programs in longitudinal studies is necessary to demonstrate its effectiveness (23). In addition, the evaluation should not only consider the primary outcome of the intervention, but should also address the implementation process and the stakeholders' experiences (13, 24-26).

Only a few studies have focused on the effectiveness of strategies that implement measures to reduce physical work demands $(27,28)$. This lack is remarkable because there is no reason to assume that workers will change their behavior when given (written) recommendations alone $(29,30)$. Implementation processes involve the encouragement of behavioral change, a process which is affected by knowledge and attitudes (31), the ability to adopt measures (32), experience with the measures to be used (33), and stakeholder collaboration (34). Furthermore, the change process may vary between persons (31) and between different stakeholders (35).

Changing the behavior of different stakeholders is a major challenge when one attempts to increase the use of measures at worksites. Rogers (36) and Prochaska \& Velicer (37) distinguished between different phases of behavioral change (knowledge, persuasion, decision, implementation, confirmation) among stakeholders when they initiated innovations. The transition to the phase of actual implementation is recognized as the major barrier. The following seven behavioral change phases have been distinguished and modified $(38,39)$ for all stakeholders with respect to the implementation of (new) measures to reduce the physical work demands of workers in the construction industry: (i) an awareness of the physical work demands, health risks and health gains associated with (no) use of ergonomic measures, (ii) an understanding of the ergonomic measures, (iii) a desire to provide or use the ergonomic measures, (iv) the intention to buy (or rent) or use the ergonomic measures, (v) the ability to use the ergonomic measures, (vi) use of the ergonomic measures (experience), and (vii) continuing use of the ergonomic measures. During each phase, or between phases, obstacles may arise that prevent stakeholders from progressing further in the process of change.

It is thought that an implementation strategy employing participatory ergonomics would intervene for different stakeholders at all behavioral change phases and, therefore, may be successful in increasing the use of measures at worksites. According to Haines et al (21), such a strategy can be defined as the involvement of people in planning and controlling a significant amount of their own work activities with sufficient knowledge and power to influence processes and outcomes to achieve desirable goals.

The main objective of this study was to evaluate the effect of the implementation strategy using participatory ergonomics to adjust work height and mechanize the transport of materials in bricklaying teams in a cluster randomized controlled design. The random allocation of clusters (ie, the bricklaying companies) is explainable by the fact that the strategy used was targeted towards bricklaying companies and, ultimately, towards the worker.

\section{Study population and methods}

This paper followed the extended guidelines for cluster randomized trials in the Consolidated Standards of Reporting Trials (CONSORT) statement (40) to provide detailed insight into the quality of the study design and to make comparisons with future randomized controlled trials easier.

\section{Participants}

In a cluster randomized controlled trial, 10 bricklaying companies were randomly assigned to an intervention group in which a participatory ergonomics strategy was implemented $(\mathrm{N}=5)$ or to a control group $(\mathrm{N}=5)$. Bricklaying teams from the companies were followed in the intervention group $(\mathrm{N}=65)$ and the control group $(\mathrm{N}=53)$ for 6 months, and their use of ergonomic measures was compared at both the company and the individual level.

The Dutch employers' association of bricklaying companies supplied information on their 178 members 
in response to a request from Arbouw (the National Occupational Health and Safety Institute in the Dutch construction industry). All 178 companies received a letter signed by the employers' association and Arbouw informing them that they may receive a phone call asking them to participate in the study.

A random sample of 50 companies was taken from the list of 178 . Twenty companies from this sample met the inclusion criterion (ie, they used measures to adjust the work height of the stored materials for $<10 \%$ of the work time). Ten eligible companies refused to participate for the following reasons: no research wanted (6 companies), too small a company ( 2 companies), too inconvenient (1 company), and workers not interested (1 company). The remainder participated in the study. All the employers were informed personally about the purpose and content of the study, and they agreed to participate by signing a letter of informed consent. At the start of the intervention, leaflets were given to the employers to inform the workers about the study.

\section{Intervention}

The intervention lasted 6 months (January-June 2003). It consisted of implementing a participatory ergonomics strategy under the guidance of a trained ergonomic consultant, the aim being to implement four types of ergonomic measures in companies and teams of bricklayers and bricklayers' assistants. These four measures were (i) the use of trestles (figure 1A) or bricklaying scaffolds (figure 1B) for adjusting work height when bricks and mortar needed to be picked up, (ii) the use of mast-climbing work platforms (figure 1C) or bricklaying scaffolds for adjusting work height for bricklaying at a wall side, (iii) the use of cranes (figure 1D) for mechanizing the transport of bricks, and (iv) the use of cranes or automatic pumping for mechanizing the transport of mortar.

The strategy used in this study (described in the appendix) was based on behavioral change phases and consisted of a six-step approach in which different company stakeholders (ie, employer, work planners, foremen, and bricklayers and bricklayers' assistants) and one ergonomics consultant participated. The change process was endorsed, planned, followed, and evaluated by a specially appointed steering group (step 1). The goals of step 1 also included clarifying the objectives of the participatory ergonomics strategy and obtaining knowledge on the intent of the majority (at least 75\%) of the members of the steering group to implement ergonomic measures. The choice of a company chairman with a financial budget (usually the employer) emphasized
Figure 1. Examples illustrating the four types of ergonomic measures implemented in the companies and the teams of bricklayers and bricklayers' assistants: use of a trestle $(A)$, a bricklaying scaffold (B), a mast-climbing work platform (C), and a crane (D).
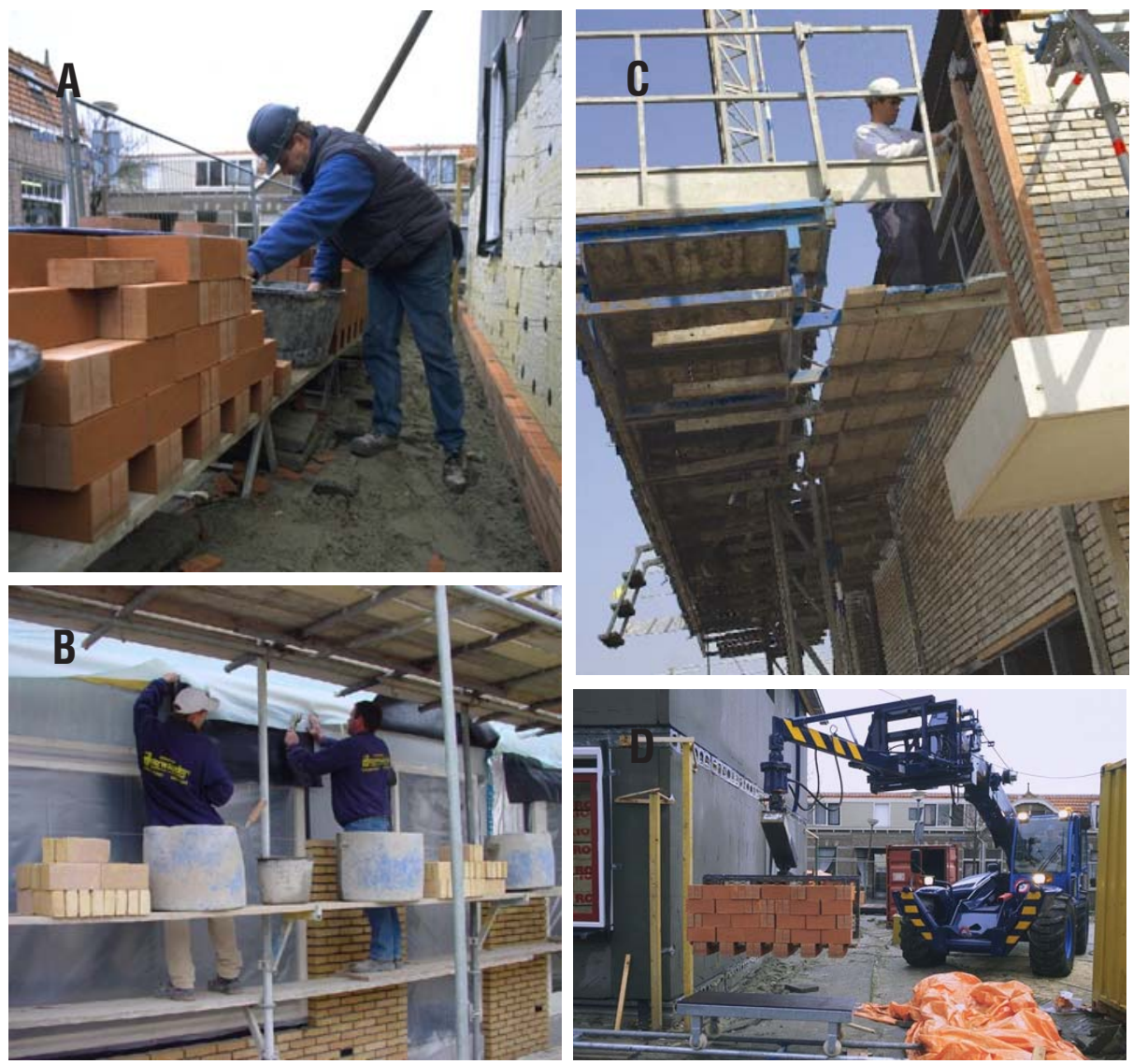
that the company was responsible and committed to adopting the participatory ergonomics strategy for implementing the ergonomic measures. Other stakeholders were included with the goal of incorporating the factors of end-user experiences (bricklayers and assistants), obtaining commitment (middle management), and allowing for the early involvement of facilitators (eg, work planners) with regard to the implementation of ergonomic measures. Ensuring the continuity of the interventions required planning at least three steering group meetings (each lasting a maximum of 2 hours), with the same members in attendance, within 6 months. These meetings addressed the identification and solution of problems and allowed the participants to share their experiences after having worked with the ergonomic measures. The experiences of ergonomic consultants from similar projects suggested that a period of 6 months allows the steering group sufficient time to perform all of the 31 activities involved in the six implementation steps. Information strategies (written, oral and visual) were applied to ensure that knowledge was disseminated about the physical work demands of bricklaying and possible measures to reduce them (step 2). At least $80 \%$ of the workers had to be informed through written information, and half of the workers through oral information (ie, meetings). In step 3, special attention was paid to tailored information about the ergonomic measures and any obstacles to the implementation. Two essential activities involved the selection of specific ergonomic measures (eg, use of trestles or bricklaying scaffolds for adapting work height) by workers $(\geq 20 \%)$ and the anticipation of obstacles hindering the implementation process. Step 4 contained a wide and varied spectrum of actions designed to facilitate the use of the selected measures. Together with eliminating obstacles, instruction and training enabled the use of ergonomic measures. Testing the measures without financial risk and performing cost-benefit analyses were thought to provide additional incentives for using the ergonomic measures. Step 5 focused on the possibility of getting acquainted with these measures before the actual implementation was planned. The two activities of the 5th step involved actually trying out the measures and - to a less extent-making adaptations based on the experiences of the stakeholders. The implementation step (step 6) incorporated feedback from the trial run (to $\geq 50 \%$ of the tester group) and the announcement of buying or renting the equipment needed to implement the ergonomic measures (to $\geq 50 \%$ of the workers), as well as agreements (eg, with a work planner, manufacturers or general contractors) concerning implementation. Information directed towards middle management (eg, foremen) and feedback about the use of the ergonomic measures directed towards all workers could further strengthen the communication, commitment, and support for incorporating the new policy (ie, the use of ergonomic measures) within the bricklaying companies.

The implementation process was guided by three external experts in the implementation of participatory ergonomics strategies (5-12 years of experience). In a special session before the start of the study, the details and duration of the approach were discussed with the experts and agreed upon. Each company could receive support from the ergonomics expert for a maximum of 6.5 workdays at no cost; the companies were required to install steering or work groups to inform and train their workers and to test the ergonomic measures used to adjust work height and mechanize the transport of materials. Each individual company was free to determine the exact realization of the six participatory ergonomic steps and the investment in time and money for implementing the ergonomic measures.

\section{Objectives}

In our study, we hypothesized that an implementation strategy employing participatory ergonomics on the company level with direct worker involvement would increase the use of recommended ergonomic measures at worksites. The following three research questions were formulated: (i) does a strategy result in an increase in the use of ergonomic measures by bricklayers and bricklayers' assistants when compared with the results of a control group in which the strategy was not introduced, (ii) does such a strategy result in alterations in the behavioral change phases related to the planned use of measures among bricklayers, bricklayers' assistants, employers, planners and foremen, and (iii) is the score of the performance indicators of such a strategy associated with an increase in the use of ergonomic measures?

\section{Outcome measurements}

Primary outcome measures. The primary outcome variable was the use of ergonomic measures. For bricklaying the measures were adjusting the height for picking up the bricks and mortar (minimum work height of $30 \mathrm{~cm}$ ) and adjusting the work height for laying the bricks at a side wall (minimum work height of $20 \mathrm{~cm}$ ). For the transport of materials the measures were mechanizing the transport of bricks and mechanizing the transport of mortar. On the cluster level, three trained observers determined the physical presence and use of the four measures at baseline and after 6 months by carrying out observations at all the worksites (a maximum of 30 minutes at each worksite) of 10 companies. The observers used a checklist with yes-no items. On the individual level, the bricklayers and bricklayers' assistants were questioned on the use of the measures at baseline and after 6 months on a 5-point ordinal Likert scale. 
Process measures. The intermediate process measures were the behavioral change phases in the intervention group. At the cluster level, the following six process measures were determined at baseline and after 6 months for the employers, work planners, and foremen: (i) awareness of the health risks and health gains associated with (no) use of ergonomic measures ("awareness"), (ii) accessibility to the ergonomic measures ("accessibility"), (iii) understanding of the ergonomic measures ("understanding"), (iv) desire to provide the ergonomic measures ("desire"), (v) intention to obtain (buy or rent) the resources needed for the ergonomic measures or the measures already in possession ("intention"), and (vi) the ability to use four types of ergonomic equipment ("ability"). These six process measures were determined by means of interviews at baseline and after 6 months. The six process measures were assessed for each interviewee and, in the case of the "intention" and "ability" phases, for four types of ergonomic equipment. The design of the interview and the relation between the items and the behavioral change phases have been reported in detail elsewhere (35). At the individual level, the following three process measures were determined at baseline and after 6 months: (i) awareness of the health risks and health gains associated with (no) use of ergonomic measures ("awareness"), (ii) desire to use the ergonomic measures ("desire"), and (iii) the skills to use the measures ("skills"). The three process measures were determined by means of two self-devised questionnaires, one for bricklaying and one for transporting materials. Both questionnaires contained three items related to "awareness" [Cronbach's alpha at baseline 0.70 (bricklaying) and 0.64 (transporting)]. The bricklaying questionnaire contained two items related to "desire" (Cronbach's alpha 0.65), and the transport questionnaire had one such item. In the case of "skills" the bricklaying questionnaire contained three items for self-efficacy (Cronbach's alpha 0.59) and one item for the possession of a scaffolding certificate. The transport questionnaire contained one item for self-efficacy and one for the possession of a crane driver's certificate.

\section{Performance indicators}

Performance indicators were used to assess the quality and execution of the intervention at the cluster and individual levels. At the cluster level, on the basis of the literature and the consensus between the consultants and the researchers, 31 performance indicators were defined for evaluating the activities of the steering group during the implementation of the strategy (appendix). Nineteen of these performance indicators were essential elements of the strategy, according to the ergonomic experts in this field. During the intervention period, the achievement of the performance indicators was observed and scored by a trained researcher during all the steering group meetings in the bricklaying companies. Two researchers were involved in these observations. One step of the strategy was achieved if the essential performance indicators were attained (yes-no items) and if, in addition, a predefined number or percentage of the steering group or nonsteering group was involved. Additional requirements were defined for the following six essential performance indicators (see the appendix): P9 (by $75 \%$ of the steering group), $\mathrm{P} 15$ (by $80 \%$ of the workers), P16 (by $50 \%$ of the workers), P20 ( $\geq 1$ or $20 \%$ of the workers), P27 (to $\geq 50 \%$ of the tester group), and P28 (to $\geq 50 \%$ of the workers). Information on these additional requirements was retrieved from observations of the steering group and the checklists that were filled out by the consultants every time the company was contacted (ie, at the meetings of the steering group, during the worksite visits, or by telephone). At the individual level, eight performance indicators were measured by means of a questionnaire, namely, "familiar with the goal of the steering group", "agree with the goal to implement measures", "information received about health risks", "information received about measures", " information about measures understandable", "information about measures convincing", "involved in choice of measures", and "tried out measures". The extent to which information about the ergonomic measures was perceived as understandable or convincing was measured on a visual analogue scale ranging from 0 ("not at all understandable or convincing") to 10 ("completely understandable or convincing").

\section{Sample size}

Sample size was not calculated because there was no adequate estimate of the main outcome measure. Due to practical constraints, a maximum of 10 companies (118 bricklayers and bricklayers' assistants) could be included.

\section{Randomization}

The random sample for recruiting eligible companies was drawn by means of a random computerized allocation procedure. The same procedure was applied for the random allocation of the companies to the intervention group or control group. Both randomizations were conducted blindly for the researcher (HM) by the second author (JS). The ergonomic consultants who guided the implementation of the participatory ergonomics strategy in the five companies of the intervention group were manually assigned by drawing lots. For practical reasons, it was decided which of the three consultants would guide only one company. Consequently, the other two each guided two companies. The implementation strategy made blind group assignment impossible for the 
participating companies, the workers, the consultants administering the strategy, and the observers of the steering group meetings.

\section{Statistical methods and analyses}

Differences in the observed (cluster level) and reported (individual level) use of ergonomic measures between the intervention and control groups were tested. At the cluster level, the difference was calculated between the proportion of locations for a given company at which the ergonomic measures were in use at baseline and at the time of the follow-up. The differences in the proportions for the intervention and control groups were examined using the Mann-Whitney-U test. At the individual level, the proportion of workers who reported using the ergonomic measures more often at the time of the follow-up than at baseline was calculated. The differences in the proportions for the intervention and control groups were examined using the chi-square test or Fisher's exact test.

For the process measures in the intervention group, McNamar's test was used to test for differences between the scores at baseline and follow-up at the individual and company levels. A particular process measure, representing a behavioral change phase, was achieved if the relevant question(s) were answered in the affirmative. For four reversed questions the negative answer was classified as positive.

The proportion of performance indicators achieved during the intervention and the proportion of workers who reported using the ergonomic measures more often after 6 months than at baseline were calculated for each company. The associations between the proportions were examined using Spearman's rho correlation coefficients.

The differences in age and years of work experience between the groups were examined using t-tests. The analyses were performed on an intention-to-treat basis. The statistical analyses were carried out using SPSS version 11.5 (SPSS Inc, Chicago, IL, USA). Statistical significance was defined as $\mathrm{P}<0.05$ for all the outcome measures.

\section{Results}

\section{Participants}

Figure 2 shows the companies (clusters) and their workers (individuals) in the various study phases. Of the 10

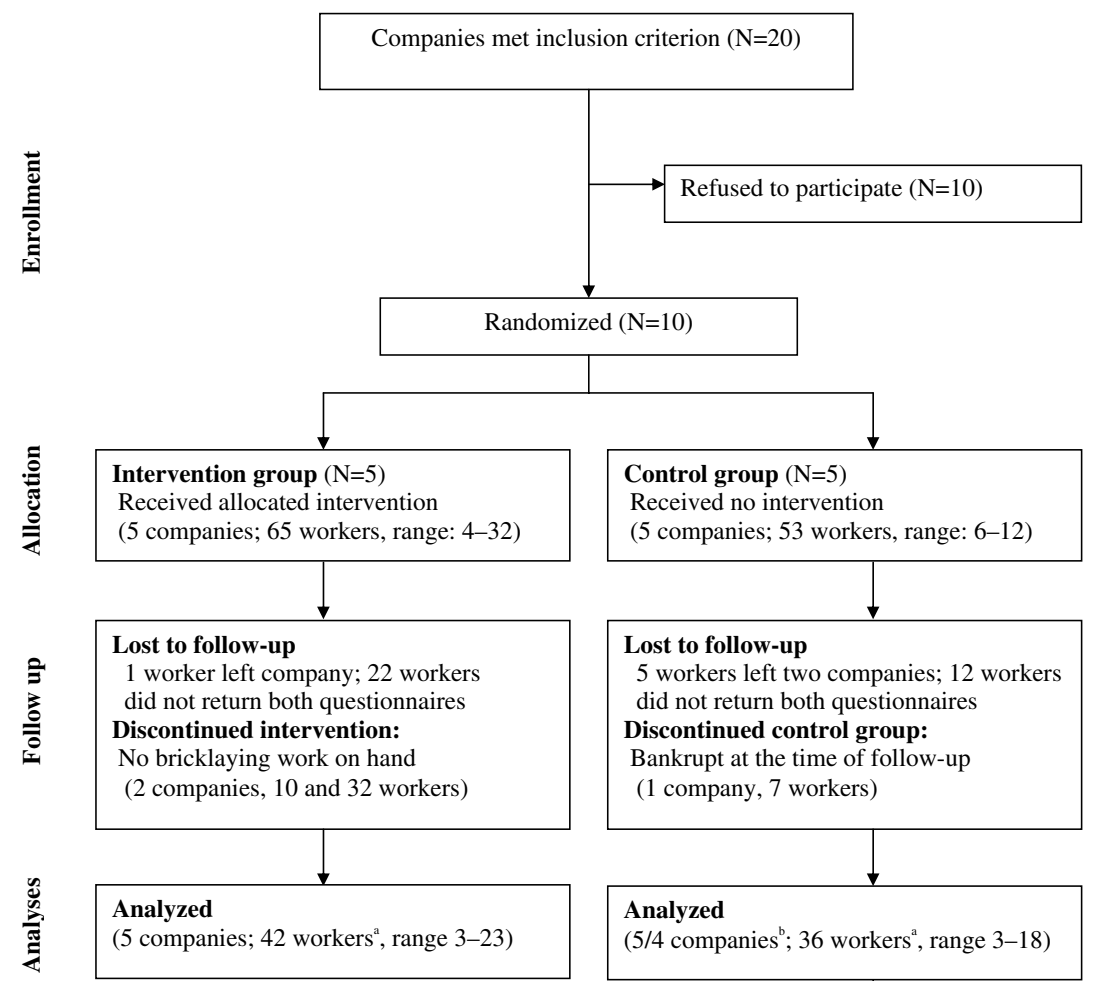

a Workers performing both bricklaying and transporting tasks were analyzed twice, as analyses were performed on bricklaying and transport questionnaires (intervention group: analysis of 33 bricklaying and 34 transporting questionnaires; control group: analysis of 29 bricklaying and 15 transporting questionnaires).

b Analysis for questionnaires based on five companies; analysis for observation at the worksites based on four companies.

Figure 2. Flow diagram of the progress of the companies and workers. 
eligible and included companies, a total of 118 people (bricklayers, bricklayers' assistants, and bricklayersbricklayers' assistants) participated in the study. At the individual level, the baseline questionnaires were returned by 111 participants (response 94\%). In the intervention group, the "lost to follow-up" was zero at the cluster level and $35 \%$ at the individual level (range per company 0-50\%) after 6 months. In the control group, the "lost to follow-up" after 6 months was one out of five companies at the cluster level and $32 \%$ at the individual level (range per company 10-50\%).

Company size and the number of worksites in each company were comparable for the intervention and control groups at baseline on the cluster level. The number of bricklayers and bricklayers' assistants in the companies varied from 4 to 9 ( 2 companies in both groups), 10 to 19 (2 intervention companies and 1 control company) and 20 to 35 (1 intervention company and 2 control companies). The number of worksites in each company varied from 2 to 4 for the intervention group and from 1 to 3 for the control group. Each worksite had its own characteristics, although the tasks were comparable. At baseline on the individual level, no significant differences in age [ 38.6 (SD 11.6) years for the intervention group versus 39.5 (SD 11.5) years for the control group], work experience [bricklaying: 20 (SD 10.4) years for the intervention group versus 20 (SD 12.4) years for the control group), transport: 18 (SD 10.7) years for the intervention group versus 20 (SD 12.0) years for the control group], and the use of the four ergonomic measures (table 1) were found between the workers in the intervention group and those in the control group.

\section{Performance indicators of the intervention on the cluster and individual levels}

The score for the performance indicators was 17 (of 19), 15 (of 19), and 7 (of 19) in three companies (table 2). Two companies agreed with the consultant to install a steering group and appointed members, but the group did not get started because of recession problems (company 2) or because there were no suitable bricklaying projects (company 3 ). None of the five companies in the intervention group managed to complete step 6 of the strategy (ie, the implementation step). Two companies reached one or more phases of the strategy (steps 1,2 , $3 \& 5$ in one and step 5 in the other).

At the individual level, around $68 \%$ of the responding workers knew the goal of the steering group and had been receiving information about the health risks and the ergonomic measures (tables 3 and 4). More than $90 \%$ of the respondents agreed with the goal of the intervention (ie, to implement ergonomic measures). The mean score for understandable and convincing information about working with the ergonomic measures was 6.6 (SD 2.6) and 5.4 (SD 2.8), respectively, for bricklaying and 6.9 (SD 2.6) and 6.8 (SD 2.5) for the transport of materials. Involvement in the choice of ergonomic measures and trying them out was relatively low for both bricklaying and transport, amounting to one-third and more than half of the workers, respectively.

Table 1. Relative frequency (RF) of the use of the measures in the intervention and control groups at baseline at the individual level.

\begin{tabular}{|c|c|c|c|c|}
\hline & \multicolumn{2}{|c|}{ Intervention group } & \multicolumn{2}{|c|}{ Control group } \\
\hline & $\mathrm{RF}^{\mathrm{a}}$ & $\%$ & $\mathrm{RF}^{\mathrm{a}}$ & $\%$ \\
\hline \multicolumn{5}{|c|}{ Use of measures in bricklaying } \\
\hline \multicolumn{5}{|c|}{ Height materials $>30 \mathrm{~cm}$} \\
\hline Almost never & $43 / 53$ & 81 & $26 / 39$ & 67 \\
\hline Sometimes & $9 / 53$ & 17 & $8 / 39$ & 20 \\
\hline Regularly & $0 / 53$ & 0 & $5 / 39$ & 13 \\
\hline Often & $1 / 53$ & 2 & $0 / 39$ & 0 \\
\hline Almost always & $0 / 53$ & 0 & $0 / 39$ & 0 \\
\hline \multicolumn{5}{|c|}{ Wall height $>20 \mathrm{~cm}$} \\
\hline Almost never & $35 / 53$ & 66 & $19 / 39$ & 49 \\
\hline Sometimes & $11 / 53$ & 21 & $15 / 39$ & 38 \\
\hline Regularly & $6 / 53$ & 11 & $4 / 39$ & 10 \\
\hline Often & $0 / 53$ & 0 & $1 / 39$ & 3 \\
\hline Almost always & $1 / 53$ & 2 & $0 / 39$ & 0 \\
\hline \multicolumn{5}{|c|}{ Use of measures in transport } \\
\hline \multicolumn{5}{|c|}{ Mechanical transport bricks } \\
\hline Almost never & $2 / 47$ & 4 & $0 / 18$ & 0 \\
\hline Sometimes & $11 / 47$ & 23 & $4 / 18$ & 22 \\
\hline Regularly & $4 / 47$ & 9 & $7 / 18$ & 39 \\
\hline Often & $6 / 47$ & 13 & $4 / 18$ & 22 \\
\hline Almost always & $24 / 47$ & 51 & $3 / 18$ & 17 \\
\hline \multicolumn{5}{|c|}{ Mechanical transport mortar } \\
\hline Almost never & $37 / 47$ & 79 & $15 / 18$ & 83 \\
\hline Sometimes & $8 / 47$ & 17 & $1 / 18$ & 6 \\
\hline Regularly & $1 / 47$ & 2 & $0 / 18$ & 0 \\
\hline Often & $0 / 47$ & 0 & $1 / 18$ & 6 \\
\hline Almost always & $1 / 47$ & 2 & $1 / 18$ & 6 \\
\hline
\end{tabular}

a Number of workers in the use category in the numerator and the total number of workers in the denominator.

Table 2. Relative frequency (RF) of achieving the performance indicators and completing the participatory ergonomics phases in the implementation of the ergonomic measures at the cluster level.

\begin{tabular}{lccccc}
\hline Company & $\begin{array}{c}\text { Performance } \\
\text { indicators } \\
(\mathrm{N}=19)\end{array}$ & & \multicolumn{2}{c}{$\begin{array}{c}\text { Participatory } \\
\text { ergonomics phases } \\
(\mathrm{N}=6)\end{array}$} \\
\cline { 2 - 3 } \cline { 5 - 6 } & $\mathrm{RF}^{\mathrm{a}}$ & $\%$ & & $\mathrm{RF}$ & $\%$ \\
\hline 1 & $15 / 19$ & 79 & & $4 / 6$ & 67 \\
3 & $0 / 19$ & 0 & & $0 / 6$ & 0 \\
4 & $0 / 19$ & 0 & & $0 / 6$ & 0 \\
5 & $17 / 19$ & 89 & & $1 / 6$ & 17 \\
\hline
\end{tabular}

a Number of performance indicators achieved or phases completed in the numerator and the total number of performance indicators or phases in the denominator. 
Table 3. Relative frequency (RF) of the workers achieving the performance indicators (indicators 1-6).

\begin{tabular}{lcc}
\hline Performance indicators & $\begin{array}{c}\text { Bricklaying } \\
\left(\mathrm{RF}^{\mathrm{a}}\right)\end{array}$ & $\begin{array}{c}\text { Transport } \\
\left(\mathrm{RF}^{\mathrm{a}}\right)\end{array}$ \\
\hline 1. Familiar with goal of steering group & $24 / 35$ & $26 / 38$ \\
2. Agree with goal to implement measures & $31 / 34$ & $35 / 38$ \\
3. Information received about health risks & $24 / 35$ & $26 / 37$ \\
4. Information received about measures & $24 / 35$ & $25 / 36$ \\
5. Involved in choice of measures & $12 / 32$ & $19 / 37$ \\
6. Trial measures & $11 / 31$ & $22 / 35$ \\
\hline
\end{tabular}

a Number of workers achieving the indicator in the numerator and the total number of workers in the denominator.
Table 4. Workers' assessment of the received information (indicators $7-8)$. ( $\mathrm{N}=$ number of workers)

\begin{tabular}{|c|c|c|c|c|c|c|}
\hline \multirow{2}{*}{$\begin{array}{l}\text { Performance } \\
\text { indicators }\end{array}$} & \multicolumn{3}{|c|}{ Bricklaying } & \multicolumn{3}{|c|}{ Transport } \\
\hline & N & Mean & SD & $\mathrm{N}$ & Mean & SD \\
\hline $\begin{array}{l}\text { 7. Information about measures } \\
\text { understandable }\end{array}$ & 29 & 6.6 & 2.6 & 31 & 6.9 & 2.6 \\
\hline $\begin{array}{l}\text { 8. Information about measures } \\
\text { convincing }\end{array}$ & 25 & 5.4 & 2.8 & 31 & 6.8 & 2.5 \\
\hline
\end{tabular}

Table 5. Relative frequency (RF) of the observed use of the four ergonomic measures at the worksites of each company in the intervention group (companies 1-5) and the control group (companies 6-10) at baseline $\left(\mathrm{T}_{0}\right)$ and after 6 months $\left(\mathrm{T}_{1}\right)$ at the cluster level. (Mat30 $=$ minimum work height of $30 \mathrm{~cm}$ for picking up bricks and mortar, Wall20 = minimum work height of $20 \mathrm{~cm}$ at a wall side, Mbricks = mechanized transport of bricks, Mmortar = mechanized transport of mortar)

\begin{tabular}{|c|c|c|c|c|c|c|c|c|}
\hline \multirow[t]{2}{*}{ Company } & \multicolumn{2}{|c|}{ Mat30 a } & \multicolumn{2}{|c|}{ Wall20 a } & \multicolumn{2}{|c|}{ Mbricks a } & \multicolumn{2}{|c|}{ Mmortar a } \\
\hline & $\mathrm{T}_{0}\left(\mathrm{RF}^{\mathrm{b}}\right)$ & $\mathrm{T}_{1}\left(\mathrm{RF}^{\mathrm{b}}\right)$ & $\mathrm{T}_{0}\left(\mathrm{RF}^{\mathrm{b}}\right)$ & $\mathrm{T}_{1}\left(\mathrm{RF}^{\mathrm{b}}\right)$ & $\mathrm{T}_{0}\left(\mathrm{RF}^{\mathrm{b}}\right)$ & $\mathrm{T}_{1}\left(\mathrm{RF}^{\mathrm{b}}\right)$ & $\mathrm{T}_{0}\left(\mathrm{RF}^{\mathrm{b}}\right)$ & $\mathrm{T}_{1}\left(\mathrm{RF}^{\mathrm{b}}\right)$ \\
\hline 1 & $0 / 3$ & $0 / 3$ & $1 / 1$ & $1 / 3$ & $0 / 3$ & $0 / 3$ & $0 / 3$ & $0 / 3$ \\
\hline 2 & $0 / 4$ & $0 / 5$ & $0 / 3$ & $2 / 5$ & $3 / 4$ & $5 / 5$ & $0 / 4$ & $0 / 5$ \\
\hline 3 & $0 / 3$ & $1 / 2$ & $1 / 2$ & $2 / 2$ & $0 / 3$ & $0 / 2$ & $0 / 3$ & $0 / 2$ \\
\hline 4 & $0 / 4$ & $1 / 2$ & $1 / 4$ & $0 / 1$ & $2 / 4$ & $2 / 2$ & $0 / 4$ & $0 / 2$ \\
\hline 5 & $0 / 2$ & $1 / 2$ & $2 / 2$ & $0 / 2$ & $0 / 2$ & $0 / 2$ & $0 / 2$ & $0 / 2$ \\
\hline 6 & $0 / 2$ & $-c$ & $1 / 1$ & $-c$ & $1 / 2$ & $-\mathrm{c}$ & $1 / 2$ & $-\mathrm{c}$ \\
\hline 7 & $0 / 1$ & $0 / 5$ & $0 / 0$ & $3 / 4$ & $0 / 1$ & $1 / 5$ & $0 / 1$ & $1 / 5$ \\
\hline 8 & $0 / 3$ & $1 / 2$ & $0 / 2$ & $1 / 2$ & $0 / 3$ & $1 / 2$ & $0 / 3$ & $0 / 2$ \\
\hline 9 & $1 / 2$ & $0 / 2$ & $0 / 2$ & $0 / 2$ & $1 / 2$ & $1 / 2$ & $0 / 2$ & $0 / 2$ \\
\hline 10 & $1 / 2$ & $0 / 2$ & $1 / 1$ & $0 / 2$ & $1 / 2$ & $2 / 2$ & $0 / 2$ & $0 / 2$ \\
\hline
\end{tabular}

a $\mathrm{P}>0.05$ between the intervention and control groups (Mann-Whitney- $U$ test).

${ }^{b}$ Number of worksites where ergonomic measures were used in the numerator and the total number of worksites in the denominator.

c Company 6 was bankrupt at the time of the observation.

Does implementing a participatory ergonomics strategy result in an increase in the use of ergonomic measures by bricklayers and bricklayers' assistants? No statistically significant intervention effect was found for the use of any of the four ergonomic measures at either the cluster or the individual level. Table 5 shows the use of the four measures at baseline and after 6 months at the cluster level. Measures to adjust the height for picking up bricks and mortar at different worksites were used more in three companies in the intervention group and in one company in the control group; in five companies the use of measures to adjust the height for picking up bricks and mortar remained the same or decreased. Two companies in the intervention group and two in the control group made more use of measures for laying wall bricks; in the other companies a decrease in use or no change was found. Measures to mechanize the transport of bricks were used more often in two companies in the intervention group, but in three companies in the control group, while use in the other four companies did not change. More use of measures to mechanize the transport of mortar occurred only in one company in the control group.
Table 6 shows the reported use of the four ergonomic measures at baseline and after 6 months of follow up at the individual level, and table 7 shows the reported increases in the use of the four ergonomic measures. The use of the different measures increased only among some workers in the intervention group and the control group. Overall, most of the respondents reported no change in the use of measures (90 times out of 134 in the intervention group and 50 times out of 88 in the control group). The reported decreases exceeded the reported increases in both the intervention group ( 27 decreases versus 17 increases) and the control group (22 decreases versus 16 increases).

Does implementating a participatory ergonomics strategy result in alterations in behavioral change phases related to the planned use of measures among bricklayers, bricklayers' assistants, employers, planners and foremen? No significant change was found in the process measures at the cluster level. For two types of ergonomic equipment (ie, trestles and cranes), a trend towards an increased ability to use these measures was found (table 8). At the individual level, self-efficacy to 
use ergonomic measures for adjusting the work height and becoming certified to adapt the work height on the scaffolding significantly increased for bricklaying (table 9). No significant changes were found for the transport of materials.

Is the score of the performance indicators of a strategy to implement participatory ergonomics associated with an increase in the use of ergonomic measures? No statistically significant correlations were found between the score of the performance indicators and more use of any of the four ergonomic measures at the company level.

\section{Discussion}

\section{Effectiveness and methodological issues}

The objective of this study was to evaluate the effect of implementing a participatory ergonomics strategy on the use of ergonomic measures by bricklaying teams. The strategy did not increase the use of ergonomic measures in bricklaying and transport. The process outcomes suggested that the ability to use ergonomic measures increased at the individual level. For bricklaying, self-efficacy and skills to adapt the work height on the scaffolding increased significantly. In addition, a trend showing an improved ability to use trestles and cranes was found for the employers, work planners and foremen. Participatory ergonomics strategies intended to stimulate the use of ergonomic measures are apparently not appropriate for either late adopters or for laggards (36), nor are they appropriate for (pre)contemplators (37). The effects of participatory ergonomics strategies on other groups, such as the early majority (36) or people in the preparation stage (37) must, however, be studied.

The lack of an increase in the use of ergonomic measures could be explained by (i) the lack of compliance, (ii) the intervention, and (iii) methodological limitations. First, compliance with the intervention was low. The performance indicators at the company and worker level did not show high scores. The economic recession during the intervention caused some companies to concentrate entirely on their core business and stop discussing and trying out ergonomic measures. In addition, the intended participation of different stakeholders and workers was not achieved within the companies. Only one company completed the preparation step. Two companies installed no steering groups, one company simply discussed the ergonomic measures and, in one company, only one bricklaying team had planned to follow the participatory ergonomics strategy. None of the companies completed the "ability to use ergonomic measures"
Table 6. Reported use (in absolute numbers) of the four ergonomic measures in the intervention group and the control group at baseline and after 6 months of follow-up at the individual level.

\begin{tabular}{ccccc}
\multicolumn{2}{c}{ Intervention group } & & \multicolumn{2}{c}{ Control group } \\
\cline { 1 - 2 } \cline { 5 - 5 } $\begin{array}{c}\text { Baseline } \\
\text { (workers } \\
\text { in } \\
\text { category) }\end{array}$ & $\begin{array}{c}\text { Follow-up } \\
\text { (workers } \\
\text { in } \\
\text { category) }\end{array}$ & $\begin{array}{c}\text { Baseline } \\
\text { (workers } \\
\text { in } \\
\text { category) }\end{array}$ & $\begin{array}{c}\text { Follow-up } \\
\text { (workers } \\
\text { in } \\
\text { category) }\end{array}$ \\
\hline
\end{tabular}

Use of measures in bricklaying a

Height materials $>30 \mathrm{~cm}$

$\begin{array}{lrrrr}\text { Almost never } & 27 & 28 & 19 & 17 \\ \text { Sometimes } & 6 & 4 & 7 & 10 \\ \text { Regularly } & - & 1 & 3 & 2 \\ \text { Often } & - & - & - & - \\ \text { Almost always } & - & - & - & - \\ \text { Wall height }>20 \mathrm{~cm} & & & & \\ \text { Almost never } & 20 & 26 & 15 & 20 \\ \text { Sometimes } & 7 & 5 & 9 & 7 \\ \text { Regularly } & 6 & 2 & 4 & 2 \\ \text { Often } & - & - & 1 & - \\ \text { Almost always } & - & - & - & -\end{array}$

Use of measures in transport ${ }^{b}$

Mechanical transport of bricks

$\begin{array}{lllll}\text { Almost never } & 1 & 2 & - & 1\end{array}$

$\begin{array}{lllll}\text { Sometimes } & 7 & 6 & 3 & 4\end{array}$

$\begin{array}{lllll}\text { Regularly } & 4 & 5 & 7 & 3\end{array}$

Often 2

Almost always 20

Mechanical transport of mortar

$\begin{array}{lllll}\text { Almost never } & 27 & 28 & 12 & 13\end{array}$

$\begin{array}{lllll}\text { Sometimes } & 6 & 3 & 1 & 1\end{array}$

Regularly

Often

Almost always

$-$

$-$

$-$

a Total number of workers 33 in the intervention group and 29 in the control group.

b Total number of workers 34 in the intervention group and 15 in the control group.

step. Consequently, there was little opportunity to detect and counterbalance obstacles to the implementation of ergonomic measures. Steering groups were planned as a means of implementing ergonomic measures among all the workers in the companies. Additional requirements were therefore defined in terms of six essential performance indicators. [See the methods section.] This fact explains the discrepancies between the achieved performance indicators and the achieved participatory ergonomics phases in company 4. It also explains the wide discrepancy between the agreement with the goal of implementing ergonomic measures and the actual involvement in the choice of these measures.

Second, the intervention itself may have contributed. It was hypothesized that, in most companies, information strategies did not suffice to increase the use of ergonomic measures at the worksites. A systematic review of this subject (9) suggested that a participatory ergonomics strategy and direct worker involvement 
Table 7. Relative frequency (RF) of the reported increase in the use of the four ergonomic measures in the intervention group (companies 1-5) and the control group (companies $6-10$ ) after 6 months of follow-up at the individual level. (Mat30 = minimum work height of $30 \mathrm{~cm}$ for picking up bricks and mortar, Wall20 = minimum work height of $20 \mathrm{~cm}$ at a wall side, Mbricks = mechanized transport of bricks, Mmortar = mechanized transport of mortar)

\begin{tabular}{|c|c|c|c|c|}
\hline Company & Mat30 a $\left(\mathrm{RF}^{\mathrm{b}}\right)$ & Wall20 ${ }^{a}\left(R^{b}\right)$ & Mbricks $^{\mathrm{a}}\left(\mathrm{RF}^{\mathrm{b}}\right)$ & $\operatorname{Mmortar}^{\mathrm{a}}\left(\mathrm{RF}^{\mathrm{b}}\right)$ \\
\hline 1 & $1 / 4$ & $2 / 4$ & $0 / 5$ & $0 / 5$ \\
\hline 2 & $2 / 21$ & $3 / 21$ & $1 / 22$ & $3 / 22$ \\
\hline 3 & $0 / 4$ & $1 / 4$ & $2 / 2$ & $0 / 2$ \\
\hline 4 & $1 / 2$ & $0 / 2$ & $0 / 2$ & $0 / 2$ \\
\hline 5 & $0 / 2$ & $0 / 2$ & $0 / 3$ & $1 / 3$ \\
\hline 6 & $1 / 3$ & $1 / 3$ & - & - \\
\hline 7 & $1 / 4$ & $1 / 4$ & $0 / 1$ & $0 / 1$ \\
\hline 8 & $4 / 5$ & $0 / 5$ & $0 / 2$ & $0 / 2$ \\
\hline 9 & $0 / 4$ & $1 / 4$ & $0 / 5$ & $1 / 5$ \\
\hline 10 & $1 / 13$ & $1 / 13$ & $4 / 7$ & $0 / 7$ \\
\hline
\end{tabular}

a $P>0.05$ between the intervention group and control group (chi-square test).

${ }^{b}$ Number of workers reporting an increase in the use of the measure in the numerator and the total number of workers per company in the denominator.

Table 8. Relative frequency (RF) of the baseline score and the change in the score after 6 months of follow-up (in absolute numbers) for the fulfilled behavioral change phases of the stakeholders (employers, planners and foremen) in the intervention group at the cluster level.

\begin{tabular}{|c|c|c|c|}
\hline \multirow[t]{2}{*}{ Behavioral change } & \multirow{2}{*}{$\begin{array}{c}\text { Baseline } \\
\text { score } \\
\left(\mathrm{RF}^{\mathrm{a}}\right)\end{array}$} & \multicolumn{2}{|c|}{ Follow-up } \\
\hline & & $\begin{array}{c}\text { In- } \\
\text { crease }\end{array}$ & $\begin{array}{l}\text { De- } \\
\text { crease }\end{array}$ \\
\hline Awareness ${ }^{b}$ & $4 / 11$ & 4 & 0 \\
\hline Accessibility ${ }^{b}$ & $8 / 11$ & 1 & 2 \\
\hline Understanding b & $9 / 11$ & 2 & 0 \\
\hline Desire to provide ${ }^{b}$ & $10 / 11$ & 1 & 0 \\
\hline \multicolumn{4}{|l|}{ Intention to buy or rent } \\
\hline Trestles $^{b}$ & $6 / 11$ & 3 & 1 \\
\hline Bricklaying scaffold b & $3 / 11$ & 3 & 0 \\
\hline Mast climbers ${ }^{b}$ & $2 / 11$ & 0 & 2 \\
\hline Cranes $^{\mathrm{b}}$ & $7 / 11$ & 3 & 0 \\
\hline \multicolumn{4}{|l|}{ Ability to use } \\
\hline Trestles $^{b}$ & $1 / 11$ & 5 & 0 \\
\hline Bricklaying scaffold b & $3 / 11$ & 3 & 2 \\
\hline Mast climbers ${ }^{b}$ & $1 / 10$ & 2 & 1 \\
\hline Cranes $^{b}$ & $3 / 11$ & 5 & 0 \\
\hline
\end{tabular}

a Number of stakeholders with fulfilled behavioral change phase in the numerator and the total number of stakeholders in the denominator.

b $\mathrm{P}>0.05$ in the pre-post score of the McNemar test.

could be effective. However, most studies were uncontrolled and the published type of studies tended to report optimistic results $(41,42)$. Only one randomized controlled trial has been reported on participatory ergonomics which aimed at reducing musculoskeletal disorders associated with manual handling tasks. Straker et al (27) found a significant effect in terms of a reduction in the risk of musculoskeletal diseases at the workplace. At the industrial level, the construction sector alone showed an increase in the risk of musculoskeletal diseases. This finding is in line with the results of our study. However, there are major differences between the study of Straker et al (27) and our study. The content of the interventions differed in each case. But, perhaps more importantly, the outcome measures at baseline and
Table 9. Relative frequency (RF) of the baseline score and change in the score after 6 months of follow-up (in absolute numbers) for the fulfilled behavioral change phases of workers in the intervention group for bricklaying and the transport of materials at the individual level.

\begin{tabular}{|c|c|c|c|c|c|c|}
\hline \multirow{3}{*}{$\begin{array}{l}\text { Behavioral } \\
\text { change }\end{array}$} & \multicolumn{3}{|c|}{ Bricklaying } & \multicolumn{3}{|c|}{ Transport } \\
\hline & \multirow{2}{*}{$\begin{array}{c}\text { Baseline } \\
\text { score } \\
\left(\mathrm{RF}^{\mathrm{a}}\right)\end{array}$} & \multicolumn{2}{|c|}{ Follow-up } & \multirow{2}{*}{$\begin{array}{c}\text { Baseline } \\
\text { score } \\
\left(\mathrm{RF}^{\mathrm{a}}\right)\end{array}$} & \multicolumn{2}{|c|}{ Follow-up } \\
\hline & & $\begin{array}{c}\text { In- } \\
\text { crease }\end{array}$ & $\begin{array}{c}\text { De- } \\
\text { crease }\end{array}$ & & $\begin{array}{c}\text { In- } \\
\text { crease }\end{array}$ & $\begin{array}{c}\text { De- } \\
\text { crease }\end{array}$ \\
\hline Awareness ${ }^{b}$ & $18 / 33$ & 4 & 3 & $27 / 34$ & 5 & 2 \\
\hline Desire $^{b}$ & $31 / 34$ & 1 & 2 & $35 / 35$ & 0 & 1 \\
\hline \multicolumn{7}{|l|}{ Skills } \\
\hline Efficacy c & $12 / 35$ & 9 & 1 & $28 / 38$ & 3 & 1 \\
\hline Certificate ${ }^{d}$ & $7 / 34$ & 6 & 0 & $5 / 35$ & 0 & 3 \\
\hline
\end{tabular}

a Number of workers with fulfilled behavioral change phase in the numerator and the total number of workers in the denominator.

b $P>0.05$ in the pre-post score of the McNemar test.

c $P=0.021$ for bricklaying and $P>0.05$ for transport in the pre-post score of the McNemar test.

d $\mathrm{P}=0.031$ for bricklaying and $\mathrm{P}>0.05$ for transport in the pre-post score of the McNemar test.

at least after 9 months of follow-up in the study of Straker et al (27) were determined by government inspectors during workplace audits. Therefore, it is plausible that a combination of two implementation strategies has been evaluated by Straker et al (27), namely, a facilitatory strategy (ie, a participatory ergonomics approach) and a compulsory strategy (ie, the two audits of the labor inspectorate). In our study three ergonomics consultants guided the implementation strategy. Differences in (inter)personal factors between the consultants could explain differences in the performance indicators of the intervention. Even so, no increase in the use of ergonomic measures was found in the companies. Finally, it is conceivable that a positive effect on the use of ergonomic measures will take longer to manifest itself than 
the 6-month period of our study, because more time may be required to realize actual changes in behavior (43). The increase in the fulfilled behavioral change phase "ability to use ergonomic measures" among the employers and workers supports this hypothesis. In addition, four out of six employers or planners and two out of five foremen or bricklayers reported that implementing the participatory ergonomics strategy had helped with the decision to implement ergonomic measures. The respondents mentioned an awareness of the high physical work demands in bricklaying teams, insistence on reducing physical work demands through ergonomic measures, and discussion time regarding the (implementation of) ergonomic measures as advantages of the participatory ergonomics approach. However, additional education or information about "best practices" and the compulsion for employers or planners, along with additional experience with the ergonomic measures for foremen or bricklayers, were frequently mentioned as activities that could enhance implementation.

Third, methodological limitations could have influenced the findings of our study. Lack of power and loss of information due to the statistical analysis could explain the negative findings. It is preferable to calculate the sample size in advance, but a precise estimation was not possible due to insufficient information about the standard deviation of our main outcome measure from comparable studies. Nevertheless, the inclusion of 57 bricklaying workers in the intervention group and 43 in the control group should theoretically make it possible to detect an effect size of 0.5 on a continuous variable at the one-sided $5 \%$ level with a power of $80 \%$. In addition, an inclusion criterion was chosen to increase the likelihood of finding an effect with a relatively small sample size. When this study was planned, we hoped to use multilevel logistic regression techniques to account for the workers being nested in companies. However, the parameter estimates in these models did not converge. There are two factors that may have contributed to this lack of convergence. First, the number of workers in some of the companies was very small. Therefore, the improvement proportion could not be really seen as a continuous variable. Second, most of the workers responded to the questions in exactly the same category at baseline and at the end point, reflecting no effect. Therefore the improvement proportion was often equal to zero. We dealt with these issues by aggregating the results at the cluster level and performing an additional analysis with them. This procedure may have resulted in a loss of information. If similar studies are carried out in the future, it is advisable to pay attention to the variation in the outcome measure being used. Bigger clusters with more workers should be selected in future studies of this kind. Finally, if randomization is to be carried out at the cluster level, it would be useful to use more clusters. However, within the constraints of our study, it was not possible to alter these factors.

We visited all of the worksites in each company to determine the presence and use of the ergonomic measures during a period of 2 weeks. The use of ergonomic measures was also assessed by means of interviews with employers and planners and with foremen and bricklayers. Questionnaires were used to measure the use of the ergonomic measures at the individual level. Measurements were thus performed at both the cluster (company) and the individual (workers) levels to detect any change in the outcome measure. Such triangulation validates the measurement of the outcome measures (ie, the use of ergonomic measures).

\section{Implications for research and practice}

It is questionable whether the steps in the participatory ergonomics implementation strategy need to be followed sequentially to increase the use of ergonomic measures at worksites. It is also disputable whether all the participatory ergonomic steps need to be followed. Despite the various intuitive theories and implementation programs based on behavioral change, there is still considerable uncertainty about the number of change phases, their sequence in different domains of application, and their effectiveness in achieving actual change (35).

Moir \& Buchholz (44) have identified several characteristics of participatory approaches that are effective in the construction industry. These characteristics are the reason for our implementing participatory ergonomics strategies even though the main question remains unanswered as to whether the implementation of participatory ergonomics strategies is effective. The findings of this randomized controlled trial suggest that a stepwise implementation strategy employing participatory ergonomics is not effective in increasing the use of ergonomic measures at worksites. In a "per protocol" analysis, the companies that passed through all the participatory ergonomics steps would have been analyzed. As a consequence, in at least some companies, full compliance with the intervention must be guaranteed. Despite the problems that were encountered in obtaining full compliance with the intervention in daily work, the stepwise strategy applied in our study was aimed at getting stakeholders involved in the implementation process of using ergonomic measures. Therefore, the "intention-totreat" principle followed in our study adds to the knowledge about the effectiveness of stepwise participatory ergonomics intervention on the use of ergonomic measures in daily work. However, because of the inclusion criterion, the results cannot be generalized to implementation strategies that apply participatory ergonomics principles in other settings. The companies in our study 
presumably belonged to the late adopters (36) or (pre)contemplators (37). Future research on the effectiveness of preventive strategies should incorporate process measures so that insight can be gained into underlying behavioral change phases such as "awareness of health risks" or "intention to change" in different stakeholder groups. Repeated measurements in the period of intervention could increase the chance of measuring actual behavioral change.

It is arguable whether all the steps of participatory ergonomics should be followed sequentially to increase the use of ergonomic measures, given the difficulties encountered by the consultants when attempting to pursue the six steps in the everyday work of construction companies. Perhaps the most important aspect of an implementation strategy that applies participatory ergonomics is getting and maintaining commitment from different stakeholders in the implementation process. In our study the commitment was formally given in the informed consent procedure with the employer, but neither financial commitments (eg, costs of the consultants or the obligation to rent or buy equipment) nor commitments with other stakeholders, such as workers or general contractors, were made. Therefore, it is recommended that commitment be increased among different stakeholders within the applied strategy, for example, by matching the ergonomics consultants and companies better or by checking the underlying behavioral change processes of individual stakeholders regularly (45). In addition, when applying participatory ergonomics, future researchers should focus more on the implementation activities that commit stakeholders to the consequences of the desired behavior. More attention to activities that discuss and share the pros and cons of the use of ergonomic measures could be an effective strategy to increase overall worker commitment to these consequences. It is advisable to take the (groups of) adopters into account when it is determined where the ergonomic measures should be implemented. Behavioral change among late adopters (36) or (pre)contemplators (37) is laborious and may take a long time. In addition, ergonomics consultants are generally not used to intervening in late-adopter groups.

\section{Acknowledgments}

We would like to thank the management, bricklayers, and bricklayers' assistants of the 10 companies in the study for their help and participation. We are also indebted to Judith Windhorst, Robin Grouwstra, and Margriet Formanoy for the data collection and to Nathalie Hugenholtz for the data processing.

\section{References}

1. Arbouw. Vermindering tilbelasting met $10 \%$ bij metselaars, stratenmakers en timmerlieden [Reducing physical work demands by $10 \%$ in bricklayers, pavers and carpenters]. Amsterdam: Arbouw; 2001.

2. Holmström EB, Lindell J, Moritz U. Low back and neck/ shoulder pain in construction workers: occupational workload and psychosocial risk factors, part 1: relationship to low back pain. Spine 1992;17:663-71.

3. Holmström EB, Lindell J, Moritz U. Low back and neck/ shoulder pain in construction workers: occupational workload and psychosocial risk factors, part 2: relationship to neck and shoulder pain. Spine 1992;17:672-7.

4. Zimmermann CL, Cook TM, Rosecrance JC. Trade specific trends in self-reported musculoskeletal symptoms and job factor perceptions among unionized construction workers. In: Seppälä P, Luopajärvi T, Nygård CH, Mattila M, editors. IEA 1997: from experience to innovation, vol. 6. Tampere (Finland): International Ergonomics Association (IEA); 1997. p 214-6.

5. Goldsheyder D, Nordin M, Weiner SS, Hiebert R. Musculoskeletal symptom survey among mason tenders. Am J Ind Med 2002;42:384-96.

6. Bernard BP, editor. Musculoskeletal disorders and workplace factors: a critical review of epidemiologic evidence for workrelated musculoskeletal disorders of the neck, upper extremity, and low back. In: Cincinnati $(\mathrm{OH})$ : National Institute for Occupational Safety and Health; 1997. Publication no 97141.

7. Fallentin N. Regulatory actions to prevent work-related musculoskeletal disorders - the use of research-based exposure limits [editorial]. Scand J Work Environ Health 2003;29(4):24750.

8. Arbo Platform Nederland [homepage on the Internet]. Netherlands: European Agency for Safety and Health at Work [updated 2001 Oct 2; cited 2004 Jul 9; available from: http:// www.arbo.nl/systems/strategies/covenants]

9. van der Molen HF, Sluiter JK, Hulshof CTJ, Vink P, FringsDresen MHW. A systematic review of the effectiveness of measures and implementation strategies to reduce physical work demands due to manual handling at work. Scand J Work Environ Health. In press.

10. Van der Molen HF, Grouwstra R, Kuijer PPFM, Sluiter JK, Frings-Dresen MHW. Efficacy of adjusting working height and mechanizing of transport on physical work demands and local discomfort in construction work. Ergonomics 2004;47(7):772-83.

11. Rootman I, Goodstadt M, Hyndman B, McQueen DV, Potvin L, Springett J, et al. Evaluation in health promotion: principles and perspectives. Copenhagen: World Health Organization (WHO); 2001. WHO regional publications, European series, no 92.

12. Noro K, Imada A. Participatory ergonomics. London: Taylor \& Francis; 1991.

13. Haines HM, Wilson JR. Development of a framework for participatory ergonomics. Sudbury (England): HSE Books; 1998.

14. Wickström G, Hyytiäinen K, Laine M, Pentti J, Selonen R. A five-year intervention study to reduce low back disorders in the metal industry. Int J Ind Ergon 1993;12:25-33.

15. Moore JS. Flywheel truing - a case study of an ergonomic intervention. Am Ind Hyg Assoc J 1994;55(3):236-44.

16. Jones RJ. Corporate ergonomics program of a large poultry 
processor. Am Ind Hyg Assoc J 1997;58(2):132-7.

17. Vink P, Urlings IJM, Van der Molen HF. A participatory ergonomics approach to redesign work of scaffolders. Saf Sci 1997;26(1/2):75-87.

18. Laitinen H, Saari J, Kivistö M, Rasa PL. Improving physical and psychosocial working conditions through a participatory ergonomic process: a before-after study at an engineering workshop. Int J Ind Ergon 1998;21(1):35-45.

19. De Jong AM, Vink P. Participatory ergonomics applied in installation work. Appl Ergon 2002;33:439-48.

20. Vink P, Lourijsen E, Wortel E, Dul J. Experiences in participatory ergonomics: results of a roundtable session during the 11th IEA Congress, Paris, July 1991. Ergonomics 1992;35, $123-7$.

21. Haines H, Wilson JR, Vink P, Koningsveld E. Validating a framework for participatory ergonomics (the PEF). Ergonomics 2002;45,309-27.

22. Westgaard RH, Winkel J. Ergonomic intervention research for improved musculoskeletal health: a critical review. Int J Ind Ergon 1997;20:463-500.

23. Kompier M. The psychosocial work environment and healthwhat do we know and where should we go? [editorial]. Scand J Work Environ Health 2002;28(1):1-4.

24. Kilböm A. Intervention programmes for work-related neck and upper limb disorders: strategies and evaluation. Ergonomics 1988;31(5):735-47.

25. Silverstein B. Design and evaluation of interventions to reduce work-related musculoskeletal disorders. In: Hagberg M, Kilbom $\AA$, editors. Book of abstracts of International Scientific Conference on Prevention of Work-related Musculoskeletal Disorders. Stockholm: PREMUS; 1992. p 1-7.

26. Goldenhar LM, La Montagne AD, Katz T, Heaney C, Landsbergis $\mathrm{P}$. The intervention research process in occupational safety and health: an overview from the national occupational research agenda intervention effectiveness research team. J Occup Environ Med 2001;43(7):616-22.

27. Straker L, Burgess-Limerick R, Pollock C, Egeskov R. A randomized and controlled trial of a participative ergonomics intervention to reduce injuries associated with manual tasks: physical risk and legislative compliance. Ergonomics 2004;47(2):166-88.

28. Pehkonen I, Riihimäki H, Hopsu L, Takala EP, Viikari-Juntura E, Leino-Arjas P, et al. Participatory ergonomic intervention in kitchen work. In: Book of abstracts of International Scientific Conference on Prevention of Work-related Musculoskeletal Disorders PREMUS. Zurich: PREMUS; 2004. p 603-4.

29. Daltroy LH, Iversen MD, Larson MG, Ryan J, Zwerling C, Fossel AH, et al. Teaching and social support: effects on knowledge, attitudes, and behaviors to prevent low back injuries in industry. Health Educ Q 1993;20(1):43-62.
30. Schenk RJ, Doran RL, Stachura JJ, Hall H. Learning effects of a back education program. Spine 1996;21(19):2183-9.

31. Haslam RA. Targeting ergonomics interventions-learning from health promotion. Appl Ergon 2002;33:241-9.

32. Kaukiainen A. Promotion of the health of construction workers [dissertation]. Tampere (Finland): University of Tampere; 2000.

33. De Jong A. Het verbeteren van arbeidsomstandigheden op de bouwplaats; innoveren op participatieve wijze [Improving working conditions at construction sites] [dissertation]. Delft (The Netherlands): University of Technology; 2002.

34. Silverstein B. Work-related musculoskeletal disorders: primary preventive strategies. In: Book of abstracts of International Scientific Conference on Prevention of Work-related Musculoskeletal Disorders PREMUS, Montreal Canada, September 1995, 21-3.

35. Van der Molen HF, Sluiter JK, Frings-Dresen MHW. Behavioural change phases of different stakeholders involved in the implementation process of ergonomics measures in bricklaying. Appl Ergon 2005;36:449-59.

36. Rogers E. Diffusion of innovations. New York (NY): The Free Press; 1995.

37. Prochaska JO, Velicer WF. The transtheoretical model of health behavior change. Am J Health Promot 1997;12:38-48.

38. Grol R, Wensing M, editors. Implementatie; effectieve verandering in de patiëntenzorg [Implementation; effective change in patient care]. Maarssen (Netherlands): Elsevier; 2001.

39. Nationaal Instituut voor Gezondheidsbevordering en Ziektepreventie (NIGZ). Introductie basisprincipes implementatie [Introduction to the basic principles of implementation]. Woerden (Netherlands): NIGZ; 2001.

40. Campbell MK, Elbourne DR, Altman DG. CONSORT statement: extension to cluster randomised trials. BMJ 2004; 328:702-8.

41. Altman DG. Practical statistics for medical research. London: Chapman and Hall; 1997.

42. Linton SJ, Van Tulder MW. Preventive interventions for back and neck pain problems: what is evidence? Spine 2001;7:77887.

43. Shannon HS, Robson LS, Sale JEM. Creating safer and healthier workplaces: role of organizational factors and job characteristics. Am J Ind Med 2001;40:319-34.

44. Moir S, Buchholz B. Emerging participatory approaches to ergonomic interventions in the construction industry. Am J Ind Med 1996;29;425-30.

45. Whysall ZJ, Haslam RA, Haslam C. Processes, barriers, and outcomes described by ergonomics consultants in preventing work-related musculoskeletal disorders. Appl Ergon 2004; 35(4):343-51.

Received for publication: 12 July 2004 


\section{Appendix}

Description of the 31 performance indicators of the implementation strategy used to apply participatory
ergonomics (the 19 performance indicators in italics were defined as essential elements in this strategy)

\begin{tabular}{|c|c|c|}
\hline \multicolumn{2}{|c|}{ Performance indicator $(\mathrm{P})$} & Explanation \\
\hline \multicolumn{3}{|c|}{ Step 1 (preparation) } \\
\hline \multicolumn{3}{|c|}{ Steering committee } \\
\hline $\begin{array}{l}\text { P1 } \\
P 2 \\
P 3 \\
P 4 \\
P 5 \\
P 6 \\
\text { P7 } \\
\text { P8 }\end{array}$ & $\begin{array}{l}\text { Company chairman } \\
\text { Financial budget by chairman } \\
\text { Bricklayer(s) } \\
\text { Bricklayers' assistant(s) } \\
\text { Work preparation } \\
\text { Worksite manager or foreman } \\
\text { Ergonomist or consultant } \\
\text { No change in steering group }\end{array}$ & $\begin{array}{l}\text { Company responsible } \\
\text { Control and facilitation of investments } \\
\text { Knowledge of hindrances-end user } \\
\text { Knowledge of hindrances-end user } \\
\text { Early involvement of facilitator } \\
\text { Commitment of middle management } \\
\text { Experiences of participatory processes } \\
\text { Ensurance of continuity }\end{array}$ \\
\hline \multicolumn{3}{|c|}{ Objectives } \\
\hline$P g$ & Subscribed objectives & Clarity and intention to implement \\
\hline \multicolumn{3}{|c|}{ Planning } \\
\hline $\begin{array}{l}\text { P10 } \\
\text { P11 } \\
\text { P12 } \\
\text { P13 } \\
\text { P14 }\end{array}$ & $\begin{array}{l}\text { Meetings }(\geq 3 \text { ) of steering committee } \\
\text { Meeting on problems } \\
\text { Meeting on solutions } \\
\text { Meeting after first experience } \\
\text { Completion within } 1 / 2 \text { year }\end{array}$ & $\begin{array}{l}\text { Ensurance of continuity } \\
\text { Knowledge of stakeholders } \\
\text { Awareness and understanding of stakeholders } \\
\text { Sharing experiences } \\
\text { More chance of success }\end{array}$ \\
\hline \multicolumn{3}{|c|}{ Step 2 (information strategies) } \\
\hline $\begin{array}{l}P 15 \\
P 16 \\
\text { P17 }\end{array}$ & $\begin{array}{l}\text { Written information } \\
\text { Oral information via meetings } \\
\text { Visual information }\end{array}$ & $\begin{array}{l}\text { Knowledge supporting implementation } \\
\text { Knowledge supporting implementation } \\
\text { Knowledge supporting implementation }\end{array}$ \\
\hline \multicolumn{3}{|c|}{ Step 3 (selection of measures) } \\
\hline $\begin{array}{l}\text { P18 } \\
\text { P19 } \\
\text { P20 }\end{array}$ & $\begin{array}{l}\text { Tailored information on measures } \\
\text { Meeting on (dis)advantages } \\
\text { Measures selected by workers }\end{array}$ & $\begin{array}{l}\text { Detailed knowledge of measures } \\
\text { Anticipation of hindrances } \\
\text { Commitment }\end{array}$ \\
\hline \multicolumn{3}{|c|}{ Step 4 (ability to use) } \\
\hline $\begin{array}{l}P 21 \\
\text { P22 } \\
P 23 \\
\text { P24 }\end{array}$ & $\begin{array}{l}\text { Instruction and training } \\
\text { Testing without financial risks } \\
\text { Intervention against hindrances } \\
\text { Cost-benefit analysis }\end{array}$ & $\begin{array}{l}\text { Knowledge and skills to use measures } \\
\text { Stimulation of experience with measures } \\
\text { Counteracting of hindrances to implementation } \\
\text { Clarity about financial consequences }\end{array}$ \\
\hline \multicolumn{3}{|c|}{ Step 5 (experiences with measures) } \\
\hline $\begin{array}{l}\text { P25 } \\
\text { P26 }\end{array}$ & $\begin{array}{l}\text { Testing measures } \\
\text { Adaptations on a trial basis }\end{array}$ & $\begin{array}{l}\text { Actual experience of measures } \\
\text { Consideration of stakeholders' experiences }\end{array}$ \\
\hline \multicolumn{3}{|c|}{ Step 6 (implementation) } \\
\hline $\begin{array}{l}\text { P27 } \\
\text { P28 } \\
\text { P29 } \\
\text { P30 } \\
\text { P31 }\end{array}$ & $\begin{array}{l}\text { Feedback from trial results } \\
\text { Announcement of deployment } \\
\text { Agreements about implementation } \\
\text { Information to middle management } \\
\text { Feedback on use of measures }\end{array}$ & $\begin{array}{l}\text { Increase in commitment through interaction } \\
\text { Communication increasing commitment } \\
\text { Support of logistics and implementation } \\
\text { Incorporation policy in organization } \\
\text { Increase in knowledge and commitment }\end{array}$ \\
\hline
\end{tabular}

